\title{
Analysis on the Characteristics of Illegal Cutting and Deforestation of Pinus kesiya in Lancang County of Yunnan Province
}

\author{
Xiaoming Xue ${ }^{1,2^{*}}$, Chenghui Nan ${ }^{1.2}$, Chenkang Deng ${ }^{1}, \mathrm{Xi} \mathrm{Liu}{ }^{1}$, Zehui Wang $^{3}$, and Bin Dao ${ }^{3}$ \\ ${ }^{1}$ Nanjing Forest Police College, Nanjing, 210023, China; \\ ${ }^{2}$ Key Laboratory of National Forestry and Grassland Administration on Wildlife Evidence Technology, Nanjing,210023, China \\ ${ }^{3}$ Yunnan Forestry Police Bureau, Kunming,650224, China
}

\begin{abstract}
Lancang county, Yunnan Province is located in the southwestern border of Yunnan Province, , China and has abundant forest resources. At the same time, there are many cases of illegal logging and deforestation in Lancang county. In the county, the cases of illegal logging and deforestation of Pinus kesiya were mainly carried out by rural personnel, the single-person case was converted into a form of gang, the remoteness of the crime site makes it difficult to find and investigate, especially in most of the rural collective forests, etc. The main reasons for its occurrence are: the general public's lack of legal awareness and economic poverty. A series of preventive measures and strike strategies, such as perfecting the system of recruiting personnel and intensifying the crackdown on such cases, were proposed to provide theoretical support for the protection and development of Pinus kesiya resources Lancang County.
\end{abstract}

\section{Preface}

Lancang County of Yunnan Province, China is located in the southern section of the Nushan Rrange in the Hengduan Mountains. The terrain is high in the northwest and low in the southeast. The five mountains and six rivers are crisscross each other. The main mountain ranges include Gongming, Kongming, Paling, Mangli and Zhafa Valley. Vertical and horizontal, there are more than 150 peaks above $2000 \mathrm{~m}$ above sea level. The highest elevation is $2516 \mathrm{~m}$ (Xincheng Township Malishan), the lowest is $578 \mathrm{~m}$ (Yakou Township Yankuang). Mountainous areas and semi-mountainous areas account for $98.8 \%{ }^{[1]}$. Chen Manming et al ${ }^{[2-4]}$ conducted a survey on the forestry situation in Lancang County. The results showed that the county had $640 \mathrm{mu}$ of forestry land, the forest coverage rate was $60.26 \%$, and the total standing stock volume was $46,737,770 \mathrm{~m}^{3}$. There are many kinds of wild animals and plants in the county. The forest trees mainly include Pinus kesiya Royle ex Gordon, Alnus cremastogyne, Schima superba and various Quercus and bamboos, with many species of Pinus kesiya and Quercus $^{[5]}$.

In the county, there are also a large number of illegal logging and deforestation. It is mainly based on Pinus kesiya, because the characteristics of the wood of Pinus kesiya are valuable in the construction materials, which drives many people to take economic interests as their purpose, to obtain windfall profits by illegal means, at any cost to damage forest resources. Forest resources are important natural, ecological and strategic resources. The protection of forest resources is of great significance to safeguarding the ecological security of the country and building an ecological civilization. General Secretary Xi Jinping has repeatedly made important instructions on strengthening the protection of forest resources, and profoundly expounded the important role of forest resources in the construction of ecological civilization. In order to protect China's forest resources, maintain the coordinated development of man and nature, promote China's ecological civilization construction, promote rural revitalization, and finally achieve common prosperity ${ }^{[6-7]}$, this paper adopts the characteristics of the case of illegal logging and deforestation of Pinus kesiya in Lancang County. The process is analyzed to provide recommendations for local ecological environmental protection.

\section{The present situation of Pinus kesiya involvement in the case}

Pinus kesiya is produced in Malipo, Simao, Puer, Jingdong and Luxi in the south of Yunnan Province, China. It forms a large area of simple forest at an altitude of 700 to 1200 meters. The tree trunk is straight and tall, fast growing, and has a wide range of wood uses. It is an afforestation tree species in the barren hills and wastelands of southern, central and western Yunnan and Xichang, Sichuan, etc. at an altitude of less than 1800 meters.

In order to get a comprehensive understanding of Pinus kesiya involvement in criminal cases, the criminal

* Corresponding author: xuexm@nfpc.edu.cn 
cases of Pinus kesiya were consulted on the website of "Chinese Judicial Documents". The statistical results show that all the cases concerning Pinus kesiya occurred in Yunnan Province.

From 2015 to 2019, there were 93 cases of illegal logging and indiscriminate felling of Pinus kesiya occurred, involving 119 people. Illegal logging and indiscriminate felling of 10149 Pinus kesiya trees with a living stock volume of $3988.45 \mathrm{~m}^{3}$.

It occurred sporadically from 2011 to 2014, with one or two cases per year, and a high incidence period from 2015 to 2018, as shown in figure 1. According to the situation of the personnel involved, there are 1 or 2 persons involved in each case, and the number of single perpetrators is relatively small.

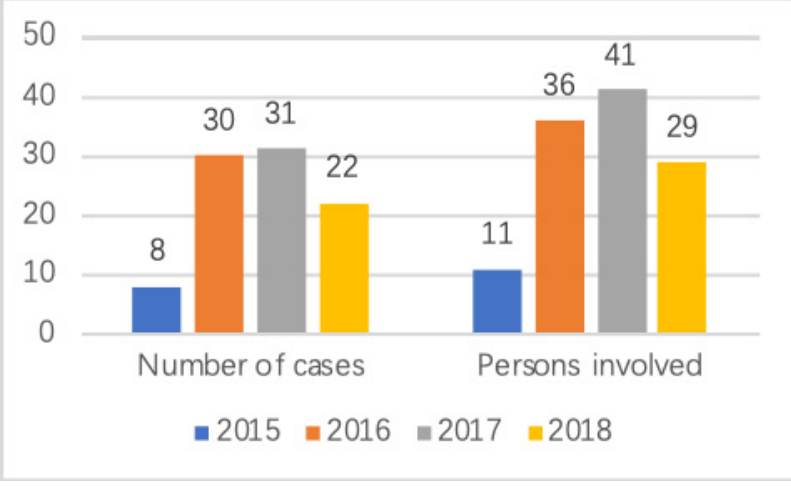

Fig. 1. Number of cases and persons involved in Pinus kesiya from 2015 to 2018

According to the number and standing volume of Pinus kesiya, the average volume of each case is more than $20 \mathrm{~m}^{3}$. As shown in Figure 2., the vast majority of documents in 2019 have not yet been uploaded to only 2 cases, but the number of cases involved is large, reaching $144.76 \mathrm{~m}^{3}$.

Next, we take Lancang County as the main summary of the characteristics of Pinus kesiya case, analyze its causes, and put forward corresponding protection countermeasures.

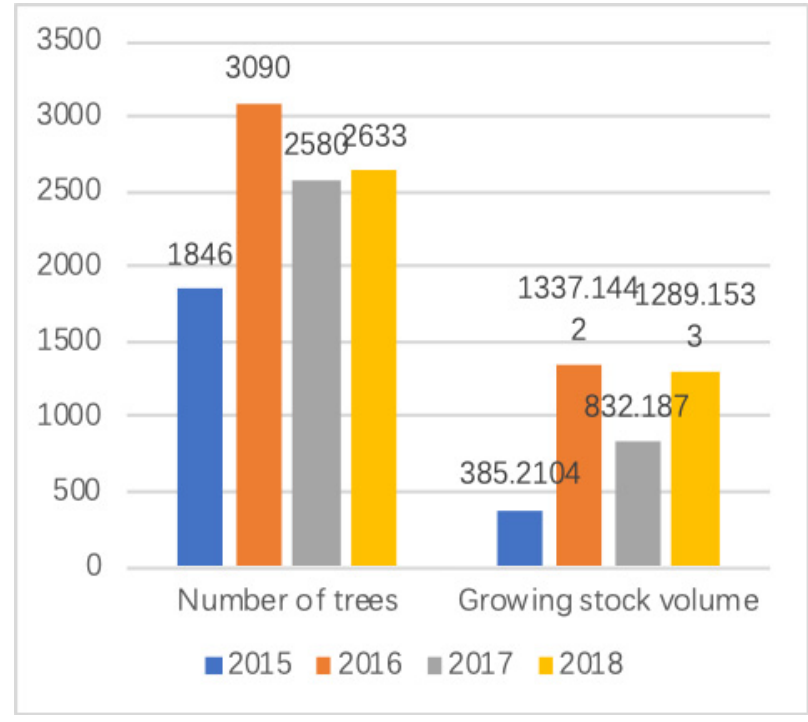

Fig 2 The number of plants and the volume of standing wood of Pinus kesiya involved in the case from 2015 to 2018

\section{Case characteristics}

\subsection{The people involved in the case are mainly farmers in rural areas with low education.}

Yunnan Province has a large number of ethnic minorities, in which ethnic minorities account for more than $50 \%$ of the persons involved, while the Han nationality accounts for $46.22 \%$. See Figure 3 for details.

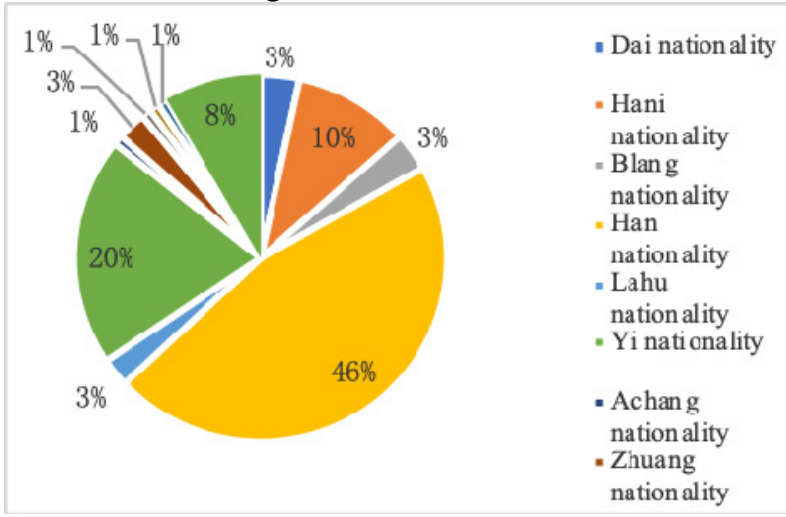

Fig 3. Ethnic situation of the persons involved in the case

The educational level of the persons involved is generally low, mostly at the level of primary and secondary schools, $41 \%$ and $36 \%$ respectively. There are 9\% illiterate persons, as shown in Figure 4.

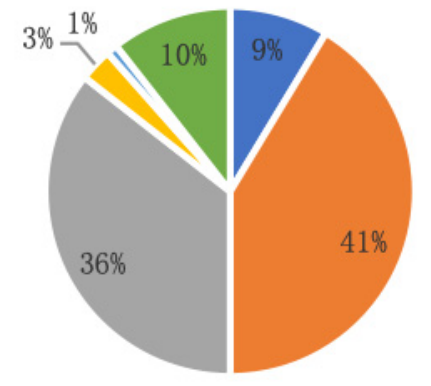

$$
\begin{aligned}
& \text { - Illiteracy } \\
& \text { - Primary school } \\
& \text { - Junior mid dle } \\
& \text { school } \\
& \text { - High sch ool }
\end{aligned}
$$

Fig 4. The educational level of the persons involved in the case

Liu Bin ${ }^{[9]}$, Li Bingkai ${ }^{[10]}$ and other people have proposed the characteristics of the peasants and agricultural personnel in the rural areas in the case of illegal logging and deforestation. $90 \%$ of the perpetrators are rural people. They live in rural areas all the year round. They know very well about the topography of the mountains and the distribution of the Pinus kesiya. They know the value of the materials used by Pinus kesiya, and they have the purpose and organized to sneak into the mountains. The cutting and clear division of labor are clear. Someone specializes in transporting the cut Pinus kesiya to the county town unloading factory, selling it at a lower price than the market price, and obtaining corresponding economic benefits. Only a small number of people are due to the need to build houses or repair houses to go to the mountains to cut down. When making transcripts for criminals, they are basically illiterate, and 
only a few people will write their own names. This shows that their level of education is very low, and there are illiterates. Because it is a minority area, there are many ethnic minorities, and some criminals do not speak Mandarin. Therefore, they can learn that they have never attended school since childhood, so that law enforcement officers and criminals lack good communication education.

\subsection{The people involved in the case mostly committed crimes in the form of single-person crimes}

The scale of their own crimes is small, the number of participants is less, and the economic benefits are not very impressive. In order to increase the intensity of the crimes and obtain more economic benefits, they are gradually transformed into organized gangs, which are highly premeditated, and the scale of the crime is large and involved. There are many people, the amount of crime is large, and the damage to the forest is more serious. The gangs have many people, arrogant and unscrupulous, often resorting to modern means of transportation, and the scope of activities is large, which brings great inconvenience to the public security organs.

\subsection{The crime location is remote, it is difficult to find and investigate}

$\mathrm{Yu}$ Yaozhou [11] proposed that the evidence in the forest-related cases is difficult to collect. The selection of forested areas by criminals is generally in remote and deep mountains, because there are abundant forest resources in the remote deep mountains, and they are organized and prepared. Of course, they also know that crimes in the mountains are safer than those around the city. It is difficult for the forest public security to find out. It is even more difficult to investigate and crack the crimes, even if the criminals are becoming more and more arrogant.

\subsection{Most of the rural collective forests are mainly based on individual contracted forests.}

There are many forest trees in the collective forest. Generally, no one will manage it and idle. The criminals feel that they are not wasted and they have the idea of breaking the law. Most of the individual contracted forests are used to plant crops or other economic tree species, change the nature of the forest, cut off the excess snails, and criminals rarely choose such forest land to commit crimes.

\section{4 the reasons for the frequent illegal logging and deforestation of Pinus kesiya}

\author{
4.1 The legal consciousness is weak and the \\ legal concept is not strong.
}

In recent years, although the publicity of the law on forest resources has been strengthened in rural areas, the propaganda of law and law has yet to be strengthened, and the effect of the law is still not obvious. Farmers' laws on the Forest Law of the People's Republic of China and the Forest Law The regulations are still not fully understood, and they are indifferent to the regulations on forest harvesting licenses in accordance with the law, and they do not take into account the illegal acts of logging trees and deforestation ${ }^{[12]}$. Lin Jinglu et al ${ }^{[13-14]}$ believe that information in remote areas is occluded, the cultural quality of ordinary people is low, and forestry laws and regulations are ignored. Ruan Guanwen ${ }^{[15]}$ believes that people have insufficient understanding of the seriousness or social harm of destroying the ecology. There is not enough social condemnation, and criminals lack stigma. It was found in the time that the villagers in Lancang County generally had the problem of cutting trees first, then issuing certificates, or simply not considering the need to apply for permits. It was not until the staff of the forest public security or forestry department came to the door to realize that their actions were illegal and criminal.

\subsection{Driven by economic interests, it led to the occurrence of deforestation and illegal logging}

At present, with the development of the market economy, the supply of timber in the timber market is tight, prices are rising, and timber revenue is high. Lin Jinglu and Huang Ying ${ }^{[13-14]}$ and other studies believe that the backwardness of the economic situation makes the people take risks when their lives are tight. In Yu Yaozhou ${ }^{[11]}$, the reason for the multiple cases involving forestry was driven by economic interests and logging to get rich. Some rural villagers often sell or rent timber belonging to the collective to the timber dealers in the form of bidding or auction for their own economic interests. After the timber dealers hand over the money to these villagers, they think they are legal. Without the approval of the forestry authorities and the handling of forest harvesting permits, hacking or even deforestation will be carried out in order to avoid paying or evading the fees and forest taxes that should be paid. Even if the forestry authorities have approved the forest harvesting permit, the time, location, quantity, and tree species that are not stipulated by the forest harvesting permit are often found ${ }^{[9]}$. For these illegal and criminal acts, some village committees or village collective organizations have left some responsibility because they have obtained some benefits.

At present, many rural areas in Lancang County, especially in the more remote mountainous areas, farmers rely on single farming to maintain their livelihood, and there are no more business channels, resulting in some farmers having less economic income, living in poverty, living pressure and culture. Under the lower real conditions, some farmers turned their attention to the trees in the mountains, and the phenomenon of illegal logging and deforestation continued to occur. 


\subsection{The competent forestry authorities are not perfect in the management of forest resources.}

Ruan Guanwen ${ }^{[15]}$ proposed that the intervention of administrative forces and the protection of the right to use the law are the thrust of the forest-related crimes. Chen $\mathrm{Xu}{ }^{[18]}$ pointed out that insufficient supervision and enforcement is a problem in the investigation and handling of forestry illegal cases. At present, the county forestry authorities are divided into Forestry bureaus,Township Forestry Stations, and nature reserves to manage forestry resources. Most of the employees of the Forestry Bureau and the Forestry Station belong to the staff who have no financial allocation but "self-support and self-support, and support the forest". However, several nature reserves in Lancang County are under the existing forestry management system. It is also heavily indebted, and most of the employees have low wages. This management model disguised the existence of deforestation. In terms of forestry resource management measures, the forestry authorities mainly control the number of trees and tree species by issuing forest harvesting permits. However, in practice, even some townships have issued forest harvesting permits, which have become "passports" for cutting or acquiring timber in the township area, which has made "legal" cover for criminal acts of illegal logging and deforestation.

\subsection{The intensity of cracking down on forest-related crimes is not big enough, not enough.}

Huang Zhanwang ${ }^{[14]}$ proposed that insufficient attention should be paid to the prevention of forest-related cases, and that fines are too low, which is an important reason for frequent cases. Chen $\mathrm{Xu}{ }^{[18]}$ pointed out that the penalty method and the random change of the penalty period are the problems in the investigation of forestry illegal cases. After the persons involved in the illegal logging and deforestation were prosecuted to the court, most of the defendants were sentenced to probation or lighter punishment after paying a certain amount of fine. This lighter penalty is good news for the people involved, but the drawbacks are obvious. On the one hand, the forest public security workers have a lot of opinions. They have paid a lot of hard-earned suspects of forest-related crimes. In the end, they have not been sentenced to substantive punishment. In the long run, forest public security workers have increased the number of punishments for forest-related crimes. On the one hand, the people involved in the crime of lightly sentenced and sentenced to forest-related crimes failed to effectively deter such personnel, and even others appeared to "proactively" imitate crimes. They realized that the cost of crime was low, once they were not caught, The forests that are stolen and deforested are their own, and once they are arrested, they are only "punishing money" and do not go to jail, which has led to the viciousness of criminal cases involving illegal logging and deforestation.

\subsection{Insufficient police force in several counties in remote areas of Yunnan}

In Lancang County, because there was not enough police force and energy to manage a large number of cases of illegal logging and deforestation, criminals seized the weakness of forest public security. At present, the county forest public security bureau has a total of 23 preparations, which is far from enough for the second largest county in Yunnan Province. Only two of the 23 establishments of the Forest Public Security Bureau of Lancang County are graduates of the police school in the true traditional sense. Others are graduated from general colleges. There is still a big gap in the understanding of the police profession. A police officer should Some qualities are completely unsuccessful in them, which also brings great difficulty to handling cases.

\section{Preventive measures and counter- measures}

\subsection{Practically strengthen the legal publicity and education of forest laws and regulations in the vast rural areas}

In order to reduce the incidence of forest-related crimes, we can carry out various forms of legal publicity and education in light of the fact that the mountainous areas are vast and the population is scattered. Through the legal publicity and education of these laws and regulations, the awareness of law-abiding is deepened in the hearts of the peasants, allowing the peasants to consciously safeguard their natural environment and fundamentally eliminate the criminal phenomenon of illegal logging and deforestation.Wu Xiaoxu ${ }^{[16]}$ proposed to publicize and launch, treat both the symptoms and the root causes, do a good job in legal propaganda, and correct the deviations in understanding. Ruan

Ruan Guanwen ${ }^{[15]}$ proposed to widely publicize and prevent problems before they happen. Cao Ronggang ${ }^{[16]}$ proposed to vigorously publicize and explain in depth, Meng Yan ${ }^{[17]}$ and others also pointed out that we must actively implement the spirit of the 19th National Congress of the Communist Party of China, take multiple measures, strengthen publicity activities, create a good atmosphere for ecological construction, and guide the masses to change from "the ecology in the eyes" to the "the ecology in the heart" to realize the people. Building a good environment for sharing ecological civilization. The Lancang County Forest Public Security Bureau should unite with the relevant departments of the Forestry Bureau to regularly publicize and educate the townships and towns to achieve timeliness, authority, and convenience. Or set up a special propaganda department to make this work more specific. 


\subsection{Expand employment channels, adjust industrial structure, and effectively increase farmers' income}

The low income of the peasants in the rural areas and the poverty of their living are an important economic reason for inducing criminal offences such as illegal logging and deforestation. Nowadays, the unemployed in the rural areas of Lancang County are addicted to alcohol and gambling. Once the money is lost, they will find ways to make money. However, they have no special skills and do not want to work hard to make a hard work. It is very difficult to find a formal job. Wu Xiaoxu ${ }^{[8]}$ proposed to implement policies, broaden the way, and open up channels for economic development through multiple channels. Li Bingkai ${ }^{[8]}$ proposed to be people-oriented and protect the economic interests of the people. Therefore, the government and relevant departments should effectively expand employment channels and The transfer of rural surplus labor in the region, helping farmers adjust the industrial structure, etc., increase the peasants' economic income, and let the peasants abandon the backward ideas of "relieving mountains and eating mountains and relying on water to eat water." There is something to do, to satisfy the peasants' desires, and to eliminate them. Good countermeasures against criminal phenomena such as illegal logging and deforestation.

\subsection{The competent forestry authorities should better perform the management of forest resources.}

Chen $\mathrm{Xu}{ }^{[18]}$ pointed out that it is necessary to strictly enforce the law and strengthen law enforcement supervision. The competent forestry authorities are the executors of laws and regulations related to forest resources. Only the executors can earnestly perform their management duties on forest resources, so that forest resources are under full security monitoring all the time, and forest resources may be subject to minimal damage. With regard to the characteristics of many towns and towns, large population and large area in Lancang County, I believe that forestry police stations should be set up in various townships and towns to strengthen management, so that the forest resources of all towns and villages are within the scope of monitoring, and the forestry in each township Cases of illegal logging and spamming can also be handled in a timely and effective manner.

\subsection{Increase the crackdown on crimes involving forests}

According to the data of the Forest Public Security Bureau of Lancang County, many people who have been hacked and abused Pinus kesiya have been repeatedly seized by the public security organs, indicating that they are all recidivists. Ruan Guanwen [15] proposed to strengthen cooperation in combating forest crimes and to work together. In order to effectively harass such recidivists and reduce the incidence of forestry crimes, forest public security, procuratorial organs, judicial organs and other political and legal organs should actively explore and build an "integrated cooperation mechanism", and strive to create information interaction, resource sharing, and both the symptoms and root causes. The crackdown on crackdowns on forest-related crimes has created a "green barrier" for forest areas and forest resources. Uniform deployment and unified arrangements for major forest-related cases should be carried out. The two organs of inspection and law must intervene in advance in major forest-related cases, fix the evidence, and make quick arrests and quick appeals. It is necessary to combine the substantive punishment with the economic penalty, from the heavy punishment of the criminals involved in the forest, to achieve the goal of "one crime in the past, ten years difficult to turn over", and truly deterred the occurrence of forest-related crimes.

\subsection{Legal supervision organs strengthen investigation and punishment}

The procuratorate should increase the intensity of the supervision of the forest-related cases and the investigation and demolition of the forestry authorities. The procuratorial organ is a special legal supervision organ of the state. Through investigation and handling of crimes involving forestry duties, it analyzes the causes of crimes, finds loopholes in the system, issues written procuratorial proposals for the whole chapter to the relevant units, and urges the units to carry out rectification and block loopholes. Effectively reduce and prevent the occurrence of forest-related crimes. At the same time, in response to the delinquency of the forestry authorities in the existing management mode, such as deforestation and illegal logging, the procuratorial organs of the procuratorial organs must step up investigation and punishment, and strictly enforce the crimes involving forestry duties. Protect forest resources so that "the sky is bluer, the water is clearer, the mountains are greener", and a harmonious nature is constructed.

\subsection{The local government should make reasonable arrangements to improve the recruitment system.}

It can be managed by region, and people or brigades can be arranged according to the corresponding proportions. Responsibility to people or to the brigade, etc., in which area occurs, find the corresponding person or brigade. For a large forestry county, the forest public security team should be adequately prepared, and there should be no shortage of preparations and lack of editing. No one will control those criminals will be even more rampant. In the future recruitment work, more conditions and strict screening should be limited. The most important thing is that the applicant must be a police school graduate. This will relieve the forest police from the work and reduce the pressure on the future development of the forest public security. It also helps a lot. 


\section{Conclusion}

Taking the case of Pinus kesiya in Lancang County as the object, the results of the analysis of the phenomenon of illegal logging and deforestation of Pinus kesiya in Yunnan Province of China shows that it is essential to strengthen the propaganda and education to the masses and reduce the occurrence of such cases from the source.

At the same time, it is also essential to strengthen management and crack down on illegal and criminal acts. Therefore, strengthening the ecological protection consciousness of the whole people is a key issue in the construction of ecological civilization.

\section{Acknowledgement}

This work is financially supported by the Fundamental Research Funds for the Central Universities (Grant Nos. LGZD201705).

\section{References}

1.Y.F.Jiang,G,DengA.D.Lu,Science of Surveying and Mapping, 36,1(2011)

2.M.M.Chen.Protection Forest Science and Technology, 3(2017)

3.Yunnan Forestry Investigation and Planning Institute,(2005)

4.D.Y.Zu.P,China Forestry Economy,6(2018)

5.C.Liu,H.Xui,G.L.Ou,Journal of Southwest Forestry University , 39,4(2019)

6.K.F.WAN,Y.J.Zhao, Journal of Anhui Agricultural Sciences, 20(2017):

7.C.N.Shi,S.B.Yao,Forestry Economics,40,3(2018)

8.X.X.Wu,Y.Gai,Journal of Heilongjiang Vocational Institute of Ecological Engineering,3(2009)

9.B.Liu,X.M.Chen,Hunan Forestry Science \& Technology ,11(2008)

10.B.K.Li,G.F.Chen,X.M.Xin,Forestry Economy,8(2007)

11.Y.Z.Yu,Private Science and Technology Journa,10(2010)

12.Y.G.Zhao,Forest Police,3(2010)

13.J.L.Li, Anhui Agricultural Science Bulletin ,19(2008)

14.Z.W.Huang,Journal of Green Science and Technology ,3(2017)

15.G.W.Ruan. Forest Police,2(2011)

16.R.G.Cao,Modern SOE Research,2(2016)

17.Y.Meng,K.H.Yu,Z.X.Zhang,H.Luo,South China Agriculture,12,29(2018)

18.X.Chen Xu.Problems and Countermeasures in the Investigation and Prosecution of Forestry Illegal Cases[N]. China Audit Daily,2017-01-11(002) 